\title{
Hybrid Polyetheretherketone (PEEK)-Acrylic Resin Prostheses and the All-on-4 Concept: A Full-Arch Implant-Supported Fixed Solution with 3 Years of Follow-Up
}

\author{
Miguel de Araújo Nobre ${ }^{1, * \mathbb{D}}$, Carlos Moura Guedes ${ }^{2}$, Ricardo Almeida ${ }^{2}$, António Silva ${ }^{3}$ and \\ Nuno Sereno 4 \\ 1 MALO CLINIC, Research and Development Department, Av. Combatentes, 43, 11, 1600-042 Lisbon, Portugal \\ 2 MALO CLINIC, Prosthodontics Department, Av. Combatentes, 43, 10, 1600-042 Lisbon, Portugal; \\ cguedes@maloclinics.com (C.M.G.); ralmeida@maloclinics.com (R.A.) \\ 3 MALO CLINIC, Ceramics, Av. Combatentes, 43, 11, 1600-042 Lisbon, Portugal; amsilva@maloceramics.com \\ 4 Invibio Biomaterial Solutions \& JUVORA, Global Technology Center, Hillhouse International, Thornton, \\ Cleveleys FY5 4QD, UK; nsereno@invibio.com \\ * Correspondence: mnobre@maloclinics.com
}

Received: 15 June 2020; Accepted: 6 July 2020; Published: 10 July 2020

\begin{abstract}
Background: The aim of this three-year prospective study was to examine the outcome of a solution for full-arch rehabilitation through a fixed implant-supported hybrid prosthesis (polyetheretherketone (PEEK)-acrylic resin) used in conjunction with the All-on-4 concept. Methods: Thirty-seven patients ( 29 females, 8 males), with an age range of 38 to 78 years (average: 59.8 years) were rehabilitated with 49 full-arch implant-supported prostheses (12 maxillary rehabilitations, 13 mandibular rehabilitations and 12 bimaxillary rehabilitations). The primary outcome measure was prosthetic survival. Secondary outcome measures were marginal bone loss, plaque and bleeding scores, veneer adhesion issues, biological complications, mechanical complications, and the patients subjective evaluation. Results: There were two patients (maxillary rehabilitations) lost to follow-up, while one patient withdrew (maxillary rehabilitation). One patient with bimaxillary rehabilitation fractured the mandibular PEEK framework, rendering a 98\% prosthetic survival rate. Implant survival was $100 \%$. Average (standard deviation) marginal bone loss at 3-years was $0.40 \mathrm{~mm}(0.73 \mathrm{~mm})$. Veneer adhesion was the only technical complication ( $n=8$ patients), resolved for all patients. Nine patients ( $n=11$ prostheses) experienced mechanical complications (all resolved): fracture of acrylic resin crowns ( $n=3$ patients), prosthetic and abutment screw loosening ( $n=4$ patients and 3 patients, respectively), abutment wearing ( $n=1$ patient). One patient experienced a biological complication (peri-implant pathology), resolved through non-surgical therapy. A $90 \%$ satisfaction rate was registered for the patients' subjective evaluation. Conclusions: Based on the results, the three-year outcome suggests the proposed rehabilitation solution as a legitimate treatment option, providing a potential shock-absorbing alternative that could benefit the implant biological outcome.
\end{abstract}

Keywords: dental implants; immediate dental implant loading; polyetheretherketone; PEEK; prostheses and implants

\section{Introduction}

Polyetheretherketone (PEEK) is a high-performance thermoplastic polymer with high strength-toweight ratio and corrosion resistance that makes it suitable as a selectable material to replace metal [1]. 
Considering its original development (Victrex plc, Lancashire, UK) [2], the fabrication process [3] results in a number of properties including chemical stability, biostability, biocompatibility, creep and wear resistance, and superior mechanical behavior. These properties allow compatibility with medical diagnostic imaging [3,4], extending its use from industrial [3] applications to those in the fields of medicine [5-9] and dentistry [6,10-15].

In the field of dentistry, the possibility of computer-aided design/computer-aided manufacturing (CAD/CAM) together with its biocompatibility and shock absorbing features $[10,16,17]$ has enabled the increased use of PEEK. These uses were extended to the fabrication of a considerable number of materials including healing caps, abutments, removable prostheses, crowns, fixed or partial full-arch dentures, and dental implants [10-15,18-23]. Despite the scarce in vivo publications, PEEK was demonstrated to be a valid treatment option compared to titanium in the rehabilitation of severely atrophic maxillary alveolar ridges both through patient-specific sub-periosteal implants [24] and as a customized mesh for bone augmentation [25].

From the psychological point of view, immediate function protocols have proven to be a benefit for the patient [26] due to the immediate restoration of mastication, phonetics, and esthetics [27]. The All-on-4 concept (Nobel Biocare, Zurich, Switzerland) involves inserting four implants for immediate function full-arch rehabilitation of edentulous jaws [28,29]. This is achieved by strategically placing four implants: two implants placed posterior with up to 45 degrees of angulation and two anterior implants in an axial orientation, providing stability in the presence $[6,7]$ or limited absence of high primary stability $(\geq 30 \mathrm{~N} \cdot \mathrm{cm})$ [30]. The long-term outcome of full-arch rehabilitation via the All-on-4 concept was recently evaluated: A high cumulative survival rate (CSR) was registered in the maxilla (94.7\% implant CSR with up to 13 years of follow-up) [31] and mandible (93\% implant CSR with up to 18 years of follow-up) [32]. In addition, the breakdown of the All-on-4 concept survival can be evaluated considering the implant CSR of $97.6 \%$ to $100 \%$ under two years [33-36], 96-99\% in three-five years [29,37-39], and $95.4-100 \%$ in 5-10 years [28,40-42]. The All-on-4 concept was further validated as a treatment option by two systematic reviews [43,44].

A previous study reported on the one-year evaluation of a hybrid solution (PEEK infrastructure with acrylic resin artificial gingiva and acrylic resin teeth) for fixed full-arch rehabilitations with the All-on-4 concept. The report registered promising short term outcomes considering the implants' survival and marginal bone loss, as well as high patient satisfaction [20] The aim of this three-year prospective study was to examine the prosthetic and implant outcomes of full-arch rehabilitations through a fixed implant-supported hybrid prosthesis (PEEK-acrylic resin) used in conjunction with the All-on-4 concept.

\section{Materials and Methods}

This prospective cohort clinical study was conducted between May 2015 and October 2019 in a private practice (Lisbon, Portugal). Patients with need of full-arch implant-supported rehabilitations experienced surgical and prosthetic intervention between May 2015 and October 2016. The study was approved by an independent ethical committee (Ethical Committee for Health, authorization No. 008/2013), (registered ClinicalTrials.gov ID NCT04446078) and all patients provided written informed consent. The study included 37 full-arch edentulous patients ( 29 females and 8 males) with an age range of 38 to 78 years (average (standard deviation): 59.8 years (10.6 years)); 12 patients with bimaxillary rehabilitations, 12 patients with maxillary rehabilitations and 13 patients with mandibular rehabilitations (total of 49 edentulous arches). The dataset was made available in an open access repository (https://osf.io/hmyux/).

\subsection{Inclusion and Exclusion Criteria}

At the treatment planning phase, inclusion and exclusion criteria were identified. Patients were included provided they had been rehabilitated with implant-supported fixed prostheses through the 
All-on-4 concept (Nobel Biocare); while patients in active chemotherapy or radiotherapy, presenting insufficient bone volume, or unable to provide written informed consent were excluded.

\subsection{Surgical and Prosthetic Protocols}

The interventions (both surgical and prosthetic protocols for All-on-4 rehabilitation) have been depicted in previous publications $[20,28,29,39,45,46]$. In brief, the implants (Nobelspeedy ${ }^{\mathrm{TM}}$, Nobel Biocare AB, Zurich, Switzerland) were inserted following standard procedures [45] except for the use of under-preparation to guarantee a final torque of over $32 \mathrm{~N} \cdot \mathrm{cm}$ before the final implant seating. The implant length ranged between 10 and $18 \mathrm{~mm}$. Four implants were inserted using distal tilting for the posterior implants (30 to 45 degrees) and two anterior implants were placed in an axial position providing support for an immediate implant-supported fixed prosthesis of high-density acrylic resin with a minimum of 10 teeth.

\subsection{Manufacture and CAD/CAM Guidelines}

As pointed out in the previous short-term report [20], the CAD/CAM guidelines relating to the cross-sectional material dimensions when designing and manufacturing the PEEK framework were: an "I" shape framework design with a minimum anterior buccal-lingual width of $4 \mathrm{~mm}$, a minimum occlusal-cervical height of $5 \mathrm{~mm}$, an increased width in the areas of the titanium sleeve to allow $6 \mathrm{~mm}$ of minimum buccal-lingual width, and a minimum of $1-2 \mathrm{~mm}$ of acrylic resin with the objective of increasing adhesion considering the previously mentioned dimensions. At the CAM phase, a titanium sleeve was introduced within the PEEK infrastructure's coronal aspect (encircled by PEEK and acrylic resin) with no special retention mechanism. This was done to prevent the titanium prosthetic screws strangulating the PEEK upon torque tightening.

\subsection{Definitive Prosthetic Protocol}

The definitive prosthetic protocol and CAD/CAM guidelines were described in detail in a previously published short-term outcome report [20]. In brief, the definitive screw-retained implant-supported prostheses provided to each patients' arch was a hybrid polymer-acrylic resin featuring a PEEK infrastructure (Juvora, Ltd., Lancashire, United Kingdom), titanium sleeves (patent No. WO2019/008368 A1) [47] as an aid to the prosthesis-abutment interface, pink acrylic resin gingiva (PalaXpress Ultra, Heraeus Kulzer GmbH, Hanau, Germany), and 12 acrylic resin teeth (Premium and Mondial crowns, Heraeus Kulzer $\mathrm{GmbH}$ ) [34]. In nine patients ( $n=9$ prostheses), the cantilever length was more than one unit. A mutually protected occlusion plan was chosen. Figure 1 illustrates a clinical case representative of the present study.

After the connection of the full-arch definitive prostheses, the patients were evaluated every six months (clinically) and at one and three years for function (clinically and radiographically).

\subsection{Outcome Measures}

We evaluated prosthetic survival as primary outcome measure (considering the necessity of replacing the prosthesis).

We evaluated implant survival, marginal bone loss, plaque scores, bleeding scores, problems during manufacturing, complications (both biological and mechanical), and the evaluation performed by the patient as secondary outcome measures.

We evaluated implant survival considering the implants' function, censoring as a failure the first implant to fail in a given patient [3]. This implied that, considering all patients had four implants supporting the prosthesis, the failure of one of the implants was marked as a failure for the patient irrespective if the remaining three implants remained in function. 

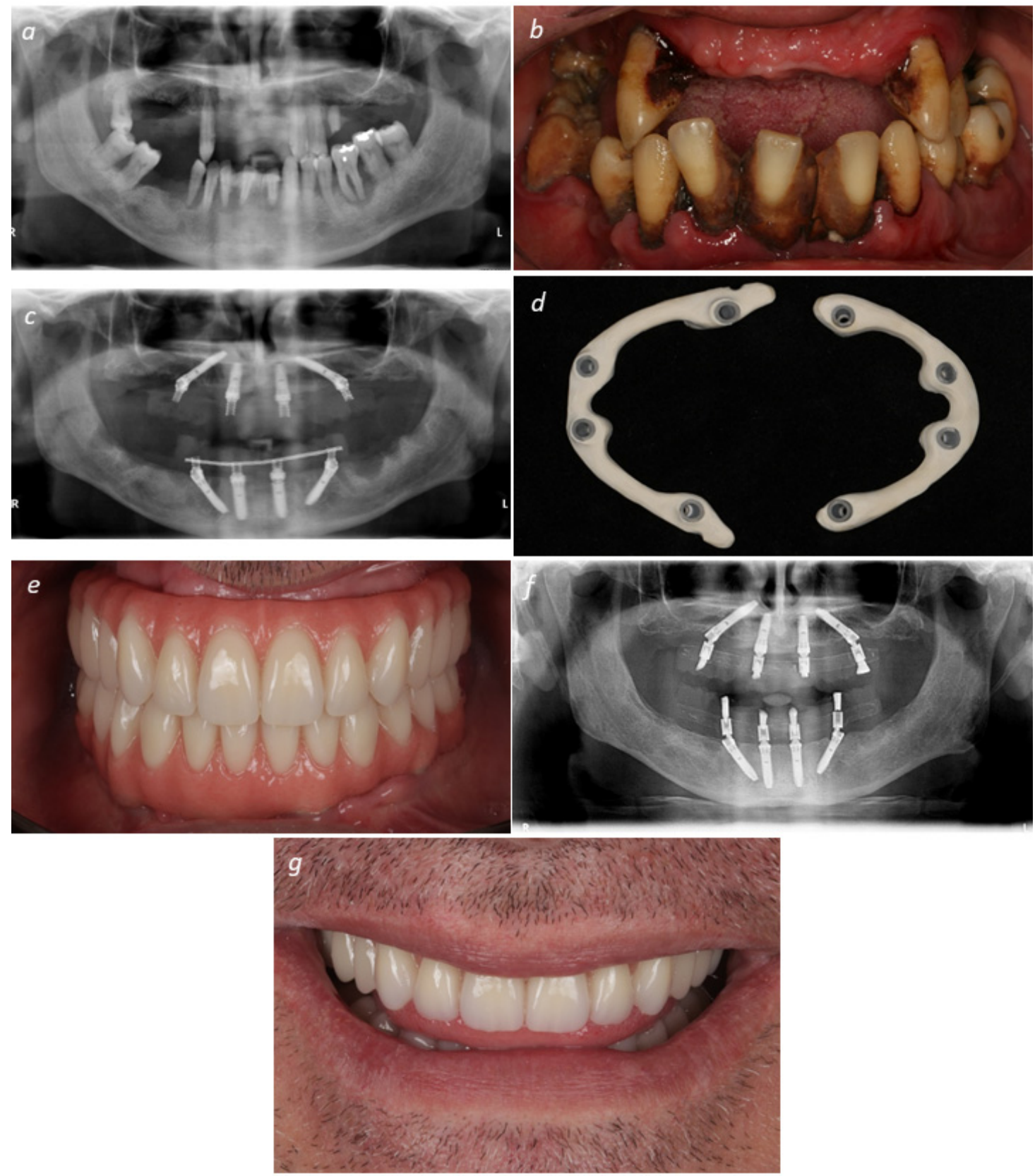

Figure 1. Representative clinical case illustrating a bimaxillary full-arch rehabilitation through a PEEK (Juvora, Ltd.) - acrylic resin (Heraeus Kulzer $\mathrm{GmbH}$ ) prostheses supported by dental implants by the All-on-4 concept (Nobel Biocare): (a) Pre-treatment orthopantomography; (b) Pre-treatment frontal view; (c) Post-treatment orthopantomography after bimaxillary restoration; (d) Polyetheretherketone (PEEK) substructure after computer-assisted manufacture (CAM); (e) Final bimaxillary rehabilitation; (f) Final post-treatment orthopantomography; (g) Post-treatment frontal view of patient smile line.

The authors examined marginal bone loss through periapical radiographs employing a radiographic holder (super-bite; Hawe Neos, Bioggio, Switzerland), adjusted for the digital film's orthognathic position. The radiographs were evaluated by an outcome assessor through software for image analysis (rayMage, version 2.3, MyRay, Imola, Italy). Marginal bone level was defined as the distance between the implant's platform and the most apical bone-implant contact, while the measurement difference between baseline (connection of the definitive prosthesis) and the three years evaluation was classified as marginal bone loss (MBL). We calibrated the measurements using the distance between implant threads and considered average values between mesial and distal sites [20]. 
Plaque levels and bleeding levels were evaluated according to the modified plaque index (mPLI) and modified bleeding index, respectively, using an ordinal scale [48].

Problems during manufacturing were evaluated considering veneer adhesion and framework integrity.

We classified adverse soft tissue reaction, suppuration, abscess, fistulae and peri-implant pathology (the presence of marginal bone loss and peri-implant pockets of more than $4 \mathrm{~mm}$, with or without the concurrent presence of bleeding on probing or suppuration) as biological complications.

We classified prosthesis, abutments or prosthetic screw fracture or loosening as mechanical complications.

The evaluations performed by the patient were registered on a visual analogue scale ranging between 0-10 (poor to excellent) and comprised the aspects: "in-mouth comfort", specified as the patients' overall evaluation according to expectations when submitting the prosthesis to function, and "overall chewing feeling", associated with the specific feeling during food mastication [20].

\subsection{Statistical Analysis}

The variables prosthetic survival and implant survival were analyzed using the prosthesis and implant as the unit of analysis, respectively. We estimated the cumulative survival rate (CSR) through life tables using the actuarial method. We calculated the mean (with 95\% confidence intervals) and standard deviation for the variables: age, MBL and the evaluations performed by the patient; for modified plaque index (mPLI) and modified bleeding index (mBI) the median was estimated; while for problems during manufacturing, biological complications and mechanical complications, we estimated frequencies. We examined the correlation between mPLI and mBI through Spearman's coefficient of correlation considering $p<0.05$ as significant. The software Statistical Package for the Social Sciences (IBM SPSS, New York, NY, USA) version 17 was used to analyze the data.

\section{Results}

\subsection{Sample}

In this study, a total of 49 full-arch restorations with an average cantilever length of $6.79 \mathrm{~mm}$ (standard deviation: $5.66 \mathrm{~mm}$; range: $0-16.5 \mathrm{~mm}$ ) per prosthesis were connected in 37 patients. There were two patients (5.4\%) with maxillary prostheses (4.1\%) lost to follow-up (throughout the first six months) as they were inaccessible, while one patient (2.6\%) with a full-arch maxillary prosthesis $(2 \%)$ withdrew from the study.

\subsection{Primary Outcome Measure}

One male patient (55 years old, heavy bruxer) with bimaxillary rehabilitation, fractured the lower arch PEEK framework prosthesis (with consequent need of replacement), rendering a 98\% prosthetic CSR (Table 1).

Table 1. Prosthetic cumulative survival rate (CSR) for hybrid polyetheretherketone (PEEK)—acrylic resin prosthetic restorations.

\begin{tabular}{ccccccc}
\hline \multirow{2}{*}{ Time } & \multirow{2}{*}{$\begin{array}{c}\text { Total Number of } \\
\text { Patients }\end{array}$} & $\begin{array}{c}\text { Total Number of } \\
\text { Prostheses }\end{array}$ & $\begin{array}{c}\text { Prosthetic } \\
\text { Failures }\end{array}$ & $\begin{array}{c}\text { Lost to } \\
\text { Follow-Up }\end{array}$ & Withdrawn & CSR \\
\hline $\begin{array}{c}\text { Prosthesis } \\
\text { connection-1 year }\end{array}$ & 37 & 49 & 1 & $2{ }^{\text {a }}$ & 0 & 98.0 \\
1 year-2 years & 35 & 46 & 0 & 0 & 0 & 98.0 \\
2 years-3 years & 35 & 46 & 0 & 0 & $1^{\mathrm{b}}$ & 98.0 \\
\hline
\end{tabular}

\subsection{Secondary Outcome Measures}

One-hundred-and-ninety-six implants were placed in order to rehabilitate a total of 49 edentulous arches. All implants remained in function, rendering a three-year $100 \%$ CSR. 
The mean (standard deviation) MBL at 1- and 3-years was $0.37 \mathrm{~mm}(0.58 \mathrm{~mm})$ and $0.40 \mathrm{~mm}$ $(0.73 \mathrm{~mm})$, respectively. Considering the MBL evaluation per arch at 1- and 3- years, the maxillary implants registered $0.33 \mathrm{~mm}(0.52 \mathrm{~mm})$ and $0.38 \mathrm{~mm}(0.77 \mathrm{~mm})$, while the mandibular implants registered $0.40 \mathrm{~mm}(0.63 \mathrm{~mm})$ and $0.42(0.70 \mathrm{~mm})$, respectively (Table 2$)$.

Table 2. Average marginal bone loss (95\% confidence intervals [CI]) and standard deviation (St. dev.) at 1- and 3-years of follow-up for single arch and bimaxillary rehabilitations.

\begin{tabular}{|c|c|c|c|c|c|c|c|}
\hline \multirow[t]{2}{*}{ Site } & & \multicolumn{2}{|c|}{ All Implants } & \multicolumn{2}{|c|}{ Medial Implants } & \multicolumn{2}{|c|}{ Distal Implants } \\
\hline & & 1 Year & 3 Years & 1 Year & 3 Years & 1 Year & 3 Years \\
\hline $\begin{array}{l}\text { Maxilla } \\
\text { Single arch }\end{array}$ & $\begin{array}{l}\text { Average }(\mathrm{mm})[95 \% \mathrm{CI}]: \\
\text { St. dev. }(\mathrm{mm}) \text { : }\end{array}$ & $\begin{array}{c}0.38 \\
{[0.21-0.54]} \\
\pm 0.83\end{array}$ & $\begin{array}{c}0.50 \\
{[0.22-0.77]} \\
\pm 0.81\end{array}$ & $\begin{array}{l}0.51 \\
{[0.23-0.78]} \\
\pm 0.13\end{array}$ & $\begin{array}{c}0.68 \\
{[0.41-0.94]} \\
\pm 0.54\end{array}$ & $\begin{array}{c}0.24 \\
{[0.04-0.45]} \\
\pm 0.10\end{array}$ & $\begin{array}{c}0.32 \\
{[0.00-0.82]} \\
\pm 1.01\end{array}$ \\
\hline $\begin{array}{l}\text { Mandible } \\
\text { Single arch }\end{array}$ & $\begin{array}{c}\text { Average }(\mathrm{mm})[95 \% \mathrm{CI}]: \\
\text { St. dev. }(\mathrm{mm}):\end{array}$ & $\begin{array}{c}0.49 \\
{[0.28-0.70]} \\
\pm 0.11\end{array}$ & $\begin{array}{c}0.48 \\
{[0.26-0.70]} \\
\quad \pm 0.77\end{array}$ & $\begin{array}{c}0.57 \\
{[0.25-0.90]} \\
\pm 0.16\end{array}$ & $\begin{array}{l}0.55 \\
{[0.23-0.86]} \\
\pm 0.76\end{array}$ & $\begin{array}{l}0.41 \\
{[0.11-0.71]} \\
\pm 0.14\end{array}$ & $\begin{array}{c}0.41 \\
{[0.09-0.74]} \\
\pm 0.79\end{array}$ \\
\hline $\begin{array}{l}\text { Bimaxillary } \\
\text { (Total) }\end{array}$ & $\begin{array}{c}\text { Average (mm) }[95 \% \mathrm{CI}]: \\
\text { St. dev. }(\mathrm{mm}):\end{array}$ & $\begin{array}{c}0.29 \\
{[0.17-0.41]} \\
\pm 0.61\end{array}$ & $\begin{array}{c}0.32 \\
{[0.18-0.46]} \\
\pm 0.67\end{array}$ & $\begin{array}{l}0.31 \\
{[0.15-0.47]} \\
\quad \pm 0.08\end{array}$ & $\begin{array}{c}0.26 \\
{[0.10-0.42]} \\
\pm 0.53\end{array}$ & $\begin{array}{c}0.27 \\
{[0.08-0.46]} \\
\pm 0.09\end{array}$ & $\begin{array}{c}0.38 \\
{[0.14-0.62]} \\
\pm 0.79\end{array}$ \\
\hline $\begin{array}{l}\text { Bimaxillary } \\
\text { (Maxilla) }\end{array}$ & $\begin{array}{c}\text { Average }(\mathrm{mm})[95 \% \mathrm{CI}]: \\
\text { St. dev. }(\mathrm{mm}):\end{array}$ & $\begin{array}{c}0.29 \\
{[0.10-0.47]} \\
\pm 0.09\end{array}$ & $\begin{array}{c}0.29 \\
{[0.06-0.51]} \\
\pm 0.73\end{array}$ & $\begin{array}{c}0.21 \\
{[0.04-0.37]} \\
\quad \pm 0.08\end{array}$ & $\begin{array}{l}0.22 \\
{[0.00-0.48]} \\
\quad \pm 0.58\end{array}$ & $\begin{array}{c}0.38 \\
{[0.00-0.77]} \\
\pm 0.18\end{array}$ & $\begin{array}{c}0.36 \\
{[0.00-0.74]} \\
\pm 0.86\end{array}$ \\
\hline $\begin{array}{l}\text { Bimaxillary } \\
\text { (Mandible) }\end{array}$ & $\begin{array}{c}\text { Average }(\mathrm{mm})[95 \% \mathrm{CI}]: \\
\text { St. dev. }(\mathrm{mm}):\end{array}$ & $\begin{array}{l}0.51 \\
{[0.16-0.86]} \\
\pm 0.16\end{array}$ & $\begin{array}{c}0.35 \\
{[0.17-0.54]} \\
\quad \pm 0.61\end{array}$ & $\begin{array}{c}0.50 \\
{[0.00-1.21]} \\
\pm 0.28\end{array}$ & $\begin{array}{l}0.31 \\
{[0.09-0.52]} \\
\quad \pm 0.48\end{array}$ & $\begin{array}{c}0.53 \\
{[0.05-1.00]} \\
\pm 0.19\end{array}$ & $\begin{array}{l}0.40 \\
{[0.07-0.73]} \\
\pm 0.73\end{array}$ \\
\hline
\end{tabular}

The scores for mPLI and mBI were characterized at six months by median scores of 1 (plaque only visible after performing the test) and 1 (isolated bleeding spot visible). On the mid-term outcome, the mPLI and mBI scores remained unaltered between 1- and 3-years of follow-up, with a median score of 2 (corresponding to visible plaque) and 1 (isolated bleeding spot visible), respectively (Figures 2 and 3 depict the mid-term outcome).

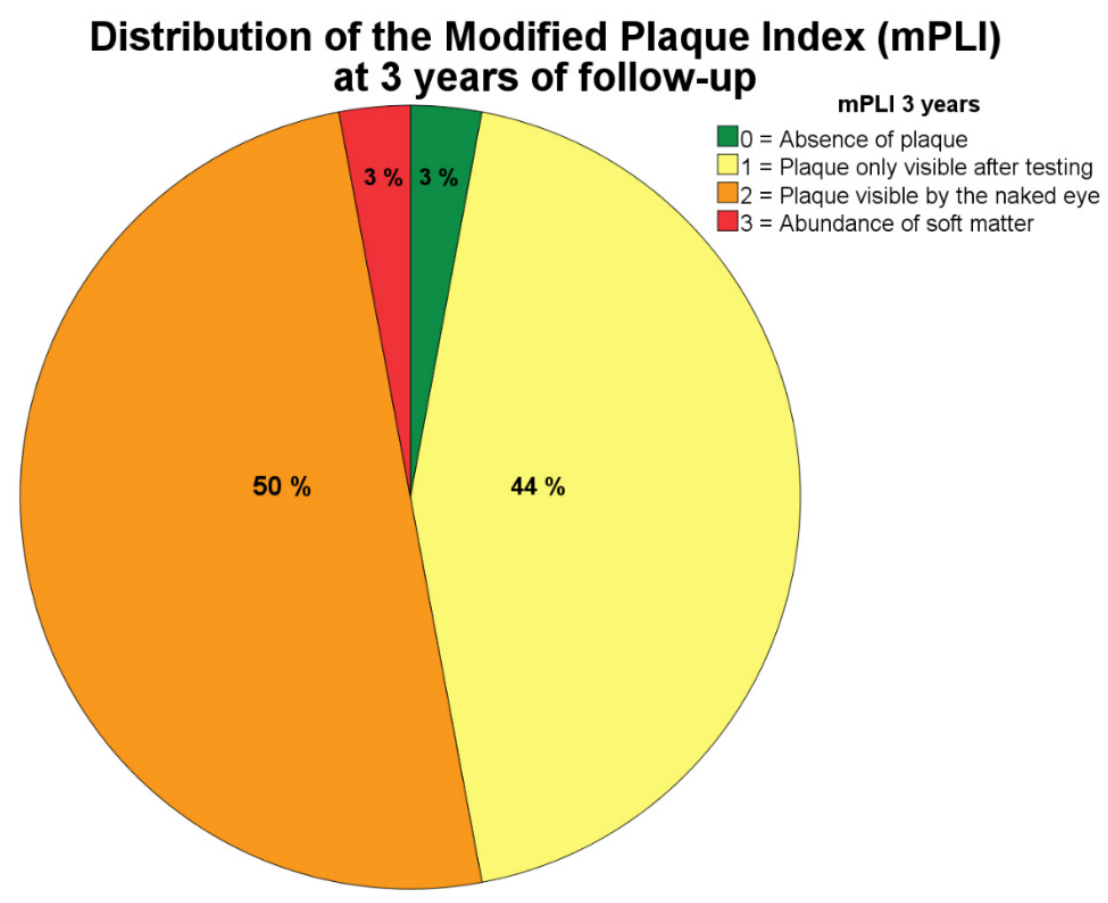

Figure 2. Distribution of modified plaque index (mPLI) at three years of follow-up. Note that majority of patients show level 2 (visible plaque). 


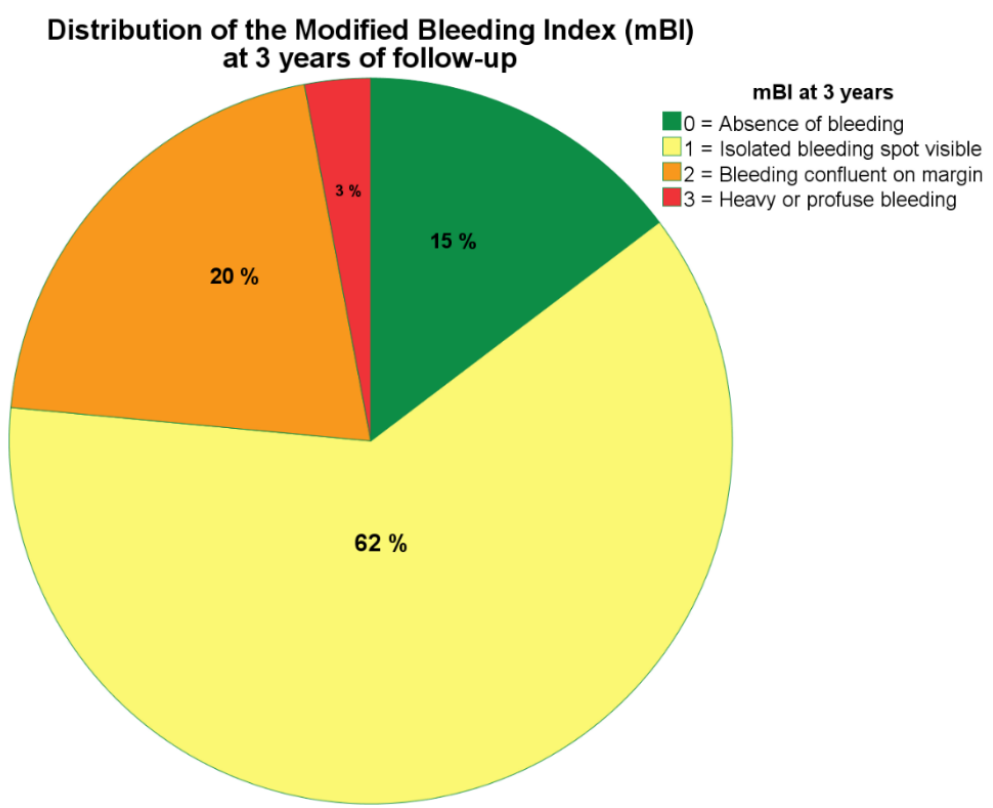

Figure 3. Distribution of the scores for modified bleeding index (mBI) at three years of follow-up. Note that majority of patients show level 1 (isolated bleeding spot visible) on the mBI.)

A weak positive correlation according to the Spearman's correlation coefficient was registered between $\mathrm{mPLI}$ and $\mathrm{mBI}$ throughout the study period at 6-months, 1 - and 3-years (Figure 4$).(R=0.408$; $p=0.017)$.

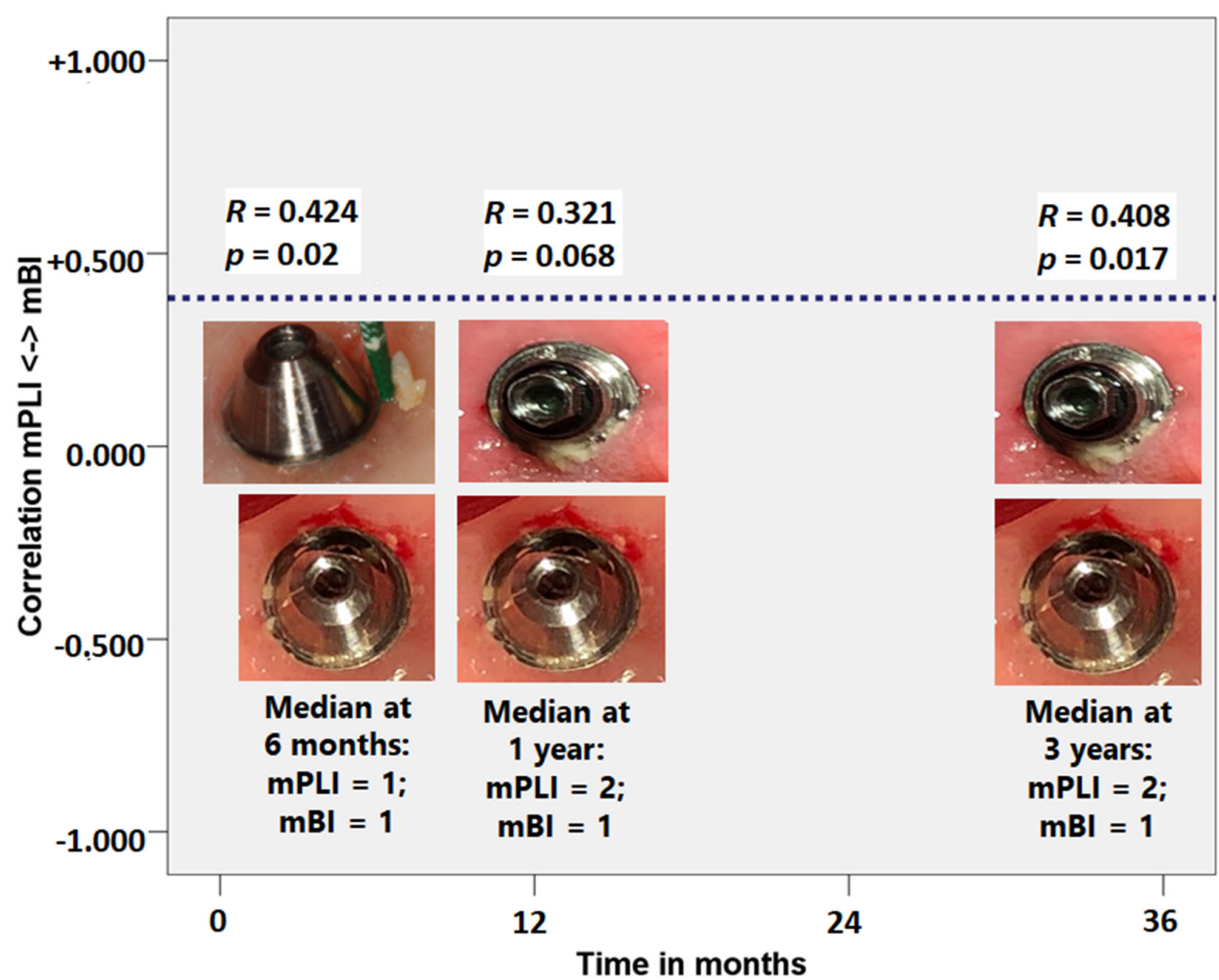

Figure 4. Correlation coefficient between plaque scores (modified plaque index - mPLI) and bleeding scores (modified bleeding index - mBI) at 6 months, 1 year and 3 years of follow-up. Note the correlations were always characterized by weak correlations. 
Veneer adhesion problems (acrylic resin avulsion from PEEK infrastructure) occurred in 10 prostheses $(20.4 \%)$ at the prosthesis level (Table 3).

The incidence of biological complications was registered at 29 months in one implant $(0.5 \%)$ that was localized in position \#35, consisting of peri-implant pathology: the implant exhibited a peri-implant pocket of $5 \mathrm{~mm}$, concurrent bleeding on probing, and a MBL of $1.6 \mathrm{~mm}$. The complication was successfully treated by non-surgical therapy, comprised of scaling, $0.2 \%$ chlorhexidine gel irrigation (Periokin gel, Kin, Barcelona, Spain), and oral hygiene instructions. No further incidences of biological complications occurred. Nine patients $(24.3 \%)$ and 11 prostheses $(22.5 \%)$ exhibited mechanical complications (Table 4) and were mainly found in patients with bimaxillary rehabilitations having, as opposing dentition, an implant-supported fixed prosthesis.

The subjective evaluation for satisfaction performed by the patient showed similar averages (standard deviation) at 1- and 3-years (Figure 5) of 88\% (16\%) and 90\% (9.5\%) for "in-mouth comfort" and $84 \%(19 \%)$ and $90 \%$ (13.6\%) for "overall chewing feeling" (Figure 5).

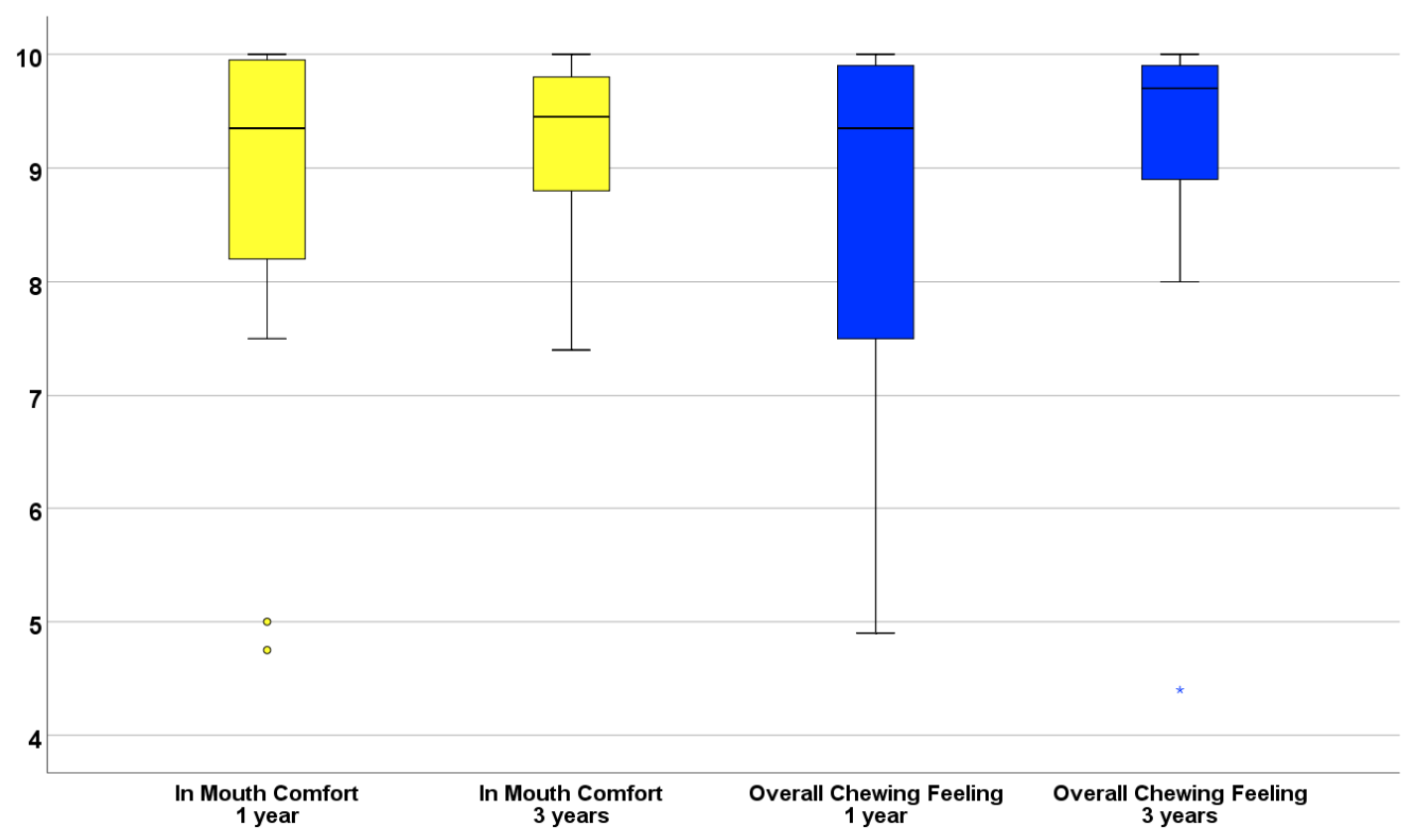

Figure 5. Box-plot illustrating patients' evaluation while using the polyetheretherketone (PEEK)-acrylic resin prostheses at 1 - and 3-years. Note that median satisfaction levels (horizontal black line inside each box) for "In mouth comfort" and "Overall chewing feeling" were registered above $80 \%$ ( $84 \%$ and $88 \%$, respectively) at one-year and at $90 \%$ (for both evaluations) at three-years. 
Table 3. Veneer adhesion problems between acrylic resin and polyetheretherketone (PEEK) infrastructure and resolution.

\begin{tabular}{|c|c|c|c|c|c|c|}
\hline Patient & Gender & Follow Up (Months) & Position (FDI) & Type Rehabilitation & Opposing Dentition & Resolution \\
\hline 1 & Male & 5 & $\# 12, \# 22, \# 25, \# 35$ & Bimaxillary & Implant-supported prosthesis & $\begin{array}{l}\text { New prostheses due to fracture of PEEK } \\
\text { infrastructure }\end{array}$ \\
\hline 2 & Male & 2 & \#35 & Mandibular & Mucosal-retained full-arch prosthesis & \\
\hline 3 & Female & 4 & \#46 & Mandibular & Natural teeth and implant-supported prosthesis & To increase flexion resistance, the cylinder \\
\hline 4 & Female & 10 & \#45 & Mandibular & Mucosal-retained full-arch prosthesis & areas were left with increased amounts of \\
\hline 5 & Female & 12 & \#35 & Mandibular & Mucosal-retained full-arch prosthesis & exposed PEEK; to increase mechanical \\
\hline 6 & Female & 12 & $\# 15, \# 22$ & Bimaxillary & Implant-supported prosthesis & retention in PEEK infrastructure, a tungsten \\
\hline 7 & Female & 16 & $\# 26$ & Maxillary & Natural teeth & bur was used; to increase tensile bond \\
\hline 8 & Female & 30 & $\# 35$ & Mandibular & Implant-supported prosthesis & strength, the bonding primer was replaced \\
\hline 9 & Male & 32 & $\# 12$ & Maxillary & Implant-supported prosthesis & \\
\hline
\end{tabular}

Table 4. Incidence of mechanical complications and resolutions during the three years of the study.

\begin{tabular}{|c|c|c|c|c|c|c|c|c|c|}
\hline Patient & Gender & $\begin{array}{l}\text { Opposing } \\
\text { Dentition }\end{array}$ & $\begin{array}{l}\text { Cantilever Units } \\
\text { (Left/Right) in mm }\end{array}$ & $\begin{array}{l}\text { Follow Up in } \\
\text { Months }\end{array}$ & $\begin{array}{l}\text { Acrylic Resin Crown } \\
\text { Fracture (Position FDI) }\end{array}$ & $\begin{array}{c}\text { Abutment Wearing } \\
\text { (Position FDI) }\end{array}$ & $\begin{array}{c}\text { Abutment Loosening } \\
\text { (Position FDI) }\end{array}$ & $\begin{array}{c}\text { Prosthetic Screw } \\
\text { Loosening (Position FDI) }\end{array}$ & Resolution \\
\hline 1 & Male & ISP & $\begin{array}{c}0 / 0 \text { (maxilla); } 10 / 10 \\
\text { (mandible) }\end{array}$ & 5 & $\# 12,22, \# 35$ & & & & $\begin{array}{l}\text { 1; Patient fractured } \\
\text { PEEK infrastructure }\end{array}$ \\
\hline 2 & Male & ISP & $13.25 / 5$ & 16 & $\# 32$ & & $\# 42$ & & 1 \\
\hline 3 & Male & ISP & $13.25 / 16.5$ & 22 & $\# 41$ & & & & 1 \\
\hline 4 & Female & NT & $10 / 10$ & 15 & & $\# 45$ & & & 2 \\
\hline 5 & Female & ISP & $10 / 5$ & 16 & & & $\# 45$ & $\# 42$ & 3 \\
\hline 6 & Female & ISP & $16.5 / 16.5$ & 16 & & & $\# 42$ & & 3 \\
\hline 7 & Female & ISP & $\begin{array}{l}\text { 10/10 (maxilla); } \\
0 / 0 \text { (mandible) }\end{array}$ & 8 & & & & $\# 25, \# 35, \# 45$ & 3 \\
\hline 8 & Female & ISP & $0 / 0$ & 4 & & & & $\# 15$ & 3 \\
\hline 9 & Male & NT & $11 / 11$ & 20 & & & & $\# 16, \# 26$ & 3 \\
\hline
\end{tabular}

ISP: Implant supports prosthesis; NT: Natural Teeth. Resolutions: 1—Mending the prostheses and adjusting occlusion; 2—Replacing the abutment and adjusting occlusion; 3—Torque controlled retightening and adjusting occlusion. 


\section{Discussion}

The present study reports the three-year outcome of a restoration solution for full-arch edentulism comprised of a fixed hybrid polymer-acrylic prosthesis with CAD/CAM infrastructure, as an alternative to other recent CAD/CAM solutions [49].

The $98 \%$ prosthetic CSR was influenced by a mandibular prosthetic failure in a bimaxillary patient presenting bruxism habit that caused a framework fracture, suggestive of occlusal overload. In a previous systematic review, Hsu et al. [50] registered bruxism and occlusal overload to be the primary etiologic factors for biomechanical complications. Moreover, previous investigations on the effect of bruxism and sex on the maximum human occlusal force recorded 978-1000 N peaks in male heavy bruxers [51,52]. In this study, despite PEEK's $1200 \mathrm{~N}$ module of deformation point (referring to the change in size or shape by an applied force) [10], the constant application of forces of this magnitude on the prosthetic materials in daily use had a negative influence on the prosthetic outcome of one patient.

The CAD/CAM guidelines for the framework (described in the Materials and Methods section) were created to compensate for material flexion, allowing a maximum of one cantilever unit and 1-2 mm acrylic resin for increased adhesion. Given the exploratory nature of this study, more than one cantilever unit $(>10 \mathrm{~mm})$ was inserted in nine prostheses of nine patients, rendering technical complications (veneer adhesion issues) more common in prosthesis with increased cantilevers, which suggested flexing of the PEEK framework distal cantilever as the potential cause. However, it should be noted that all problems related to the adhesion between PEEK and acrylic resin materials were solved regardless of the cantilever length and without prejudice to implant and prosthetic survival, underlining the importance of the proper bonding primer.

A previous study investigating All-on-4 restorations and considering different implant distributions reported a protective effect for absence of cantilever units (odds ratio $=0.22$ ) and a risk effect for bruxism (odds ratio $=60.95$ ) when examining mechanical complications [46]. In this study, similar findings were registered: bruxism influenced the incidence of mechanical complications as represented by the framework and prosthetic fractures in one patient.

The registered $100 \%$ implant CSR of the present study is comparable to recent publications for the All-on-4 concept. Maló et al. (2019) [31,32] reported three-year CSR of 97.8\% and 99.1\% for the maxilla [31] and mandible [32]. Furthermore, a systematic review evaluating the All-on-4 treatment concept registered a 99.8\% implant CSR for All-on-4 restorations with a follow-up of two or more years [44].

The mean MBL at three years of follow-up demonstrated the stability of the rehabilitations over this period, as compared to the difference of $0.03 \mathrm{~mm}$ of mean MBL registered in the previous one-year report [20]. Moreover, the MBL recorded in the present study at three years compares favorably with previous studies reporting a range of $1.06-1.52 \mathrm{~mm}$ for the maxilla $[29,53]$ and $1.30 \mathrm{~mm}$ overall for both maxilla and mandible [41]. In a systematic review [54] comparing marginal bone loss between axial and tilted implant-supported fixed prosthetic reconstructions, a range of $0.91-1.55 \mathrm{~mm}$ and $0.72-1.67 \mathrm{~mm}$ was registered after three years of follow-up of full-arch restorations for axial and tilted implants, respectively (data extracted from study). The potential explanation of this lower MBL could be associated with PEEK's characteristics of shock absorption, given its $1200 \mathrm{~N}$ cut-off point for plastic deformation (important in load-bearing areas) [10].

The median for mPLI was elevated, corresponding to visible plaque (score 2 of the mPLI scale) and consistent with inadequate oral hygiene habits; while the isolated bleeding spots around the implants recorded as median mBI level was considered mild (score 1 of the $\mathrm{mBI}$ scale). The causal association between plaque accumulation and mucositis has been reported by other authors $[55,56]$ who observed an increased severity of mucositis ( $\pm 1 \mathrm{~mm}$ increase in peri-implant probing depths accompanied by inflammation) [55] that suggested a positive linear relationship [56] when patients ceased all self-care efforts for three weeks (with undisturbed plaque accumulation). Additionally, they observed a negative linear relationship between plaque and bleeding scores (decrease in both indices) once the period of optimal plaque control was restored [56], claiming causality between plaque buildup and decreased 
peri-implant health. The same was not confirmed in the present study given the significant yet weak positive correlation between mPLI and mBI scores. From an epidemiological point of view, analyzing this result in conjunction with the very low incidence of biological complications registered in this study opens the possibility that peri-implant pathology could be triggered by more than one causal mechanism, instead of the disease development being purely driven by a biofilm-mediated infection. Furthermore, the biomechanical component could play a role in the causal mechanism considering the component causal model [57] as previously suggested [58,59].

The study registered a significantly important rate of veneer adhesion problems between PEEK and acrylic resin that the authors attribute to the learning curve and the choice of an inappropriate bonding agent. Veneer adhesion problems related to mechanical and chemical retentions between the acrylic resin and PEEK infrastructure led to the use of a bonding primer with a higher tensile bond strength, supported by the results of previous investigations $[11,60]$, in order to resolve the adhesion issues. Moreover, the cylinder area was reinforced by increasing the amount of exposed PEEK. These modifications were introduced taking into consideration PEEK flexion capacity and were detailed in the previous one-year report [20] Adhesion issues were considered part of the learning curve in the manufacturing process of the PEEK-acrylic resin restorations. Considering the authors' experience, it is advisable to comply with the following measures (additional to the CAD/CAM guidelines previously described) to prevent veneer adhesion issues: choose a correct bonding agent that enables strong chemical retention; provide a rough finish, vertical threads in the cantilever area and a horizontal thread in the remaining PEEK infrastructure (not a smooth and round finish); and enable an increased amount of exposed PEEK on the cylinder areas (Figure 6).
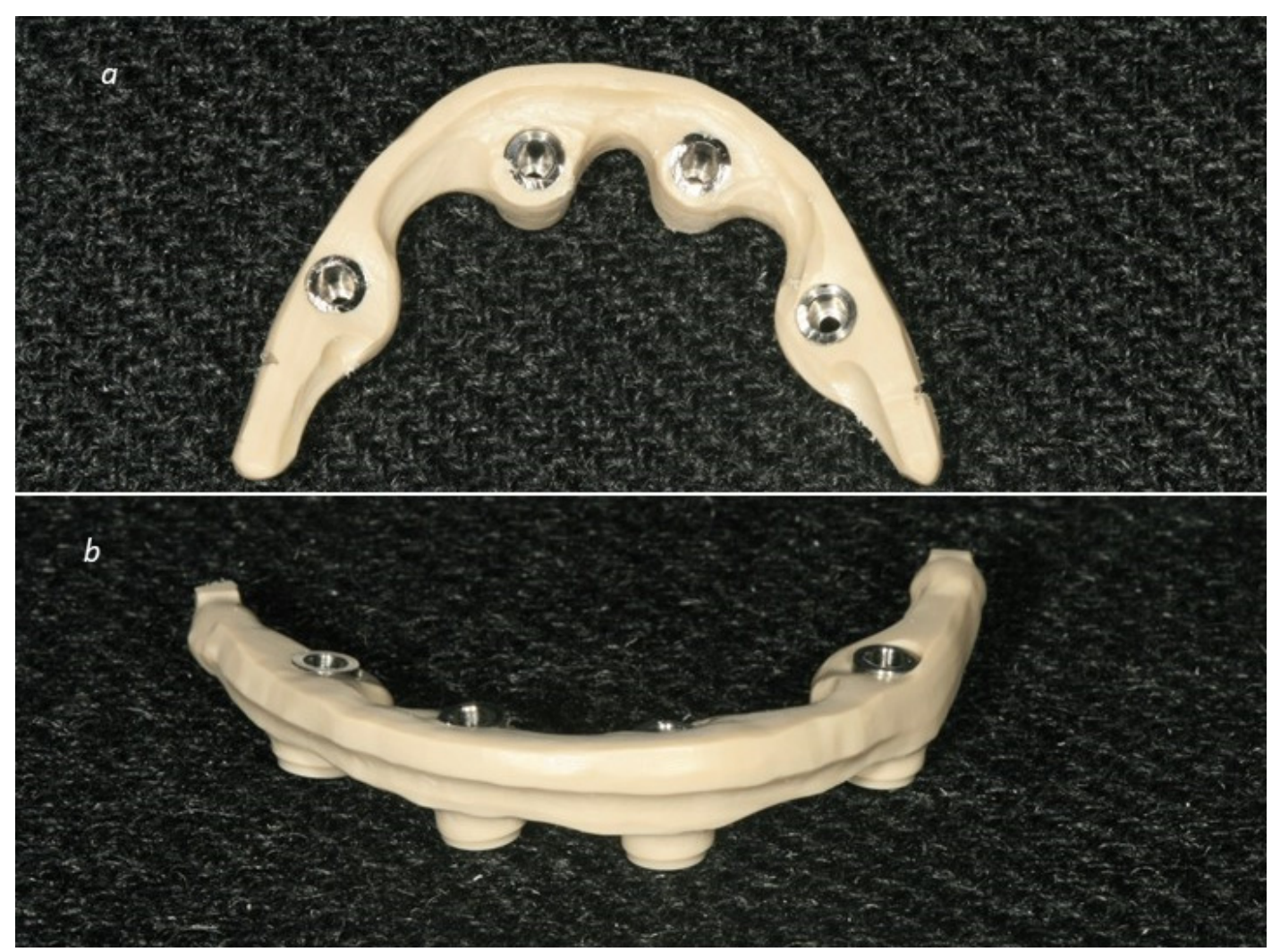

Figure 6. Additional guidelines to prevent veneer adhesion issues. (a) Infrastructure inferior view: note the finish, vertical threads on the cantilever area and the enabling of an increased amount of exposed polyetheretherketone (PEEK) on the cylinder areas; (b) Infrastructure superior view: note the horizontal thread in the remaining PEEK infrastructure (not smooth and round finish). 
With respect to the mechanical complications, the $22.5 \%$ incidence at prosthetic level was significantly influenced by their occurrence in bimaxillary rehabilitated patients (seven out of nine patients). This trend was reported in a previous investigation comparing bimaxillary and single-arch patients using the same All-on-4 rehabilitation protocol, where a significant difference in mechanical complications was registered in bimaxillary rehabilitated patients during the five-year investigation [61].

The incidence of biological complications was limited to one episode of peri-implant pathology, which was resolved non-surgically. The percentage of peri-implant pathology (0.5\%) compares favorably to other studies using the same rehabilitation protocol (All-on-4) in the same period. Maló et al. reported a 3\% and 2.1\% incidence at implant level during the first three years of follow-up for maxillary [31] and mandibular rehabilitations [32], respectively. The incidence rate was also lower as compared to a previously published systematic review that reported a peri-implant pathology with a five-year estimate of $5.4 \%$ at the implant level [62]. Considering the influence of biomechanical factors as risk indicators for peri-implant disease [58], it is important to consider the potential positive influence of the PEEK framework on this lower incidence. This is based on the previously discussed biomechanical properties of the PEEK material [10], together with the present study's low mBI scores compared to the high mPI scores. Nevertheless, a longer follow-up of at least five years is mandatory to evaluate this outcome with better precision.

The patients' overall satisfaction with the restorations was reflected by the very high values $(90 \%)$ scored in both classes, "in-mouth comfort" and "overall chewing feeling". Moreover, it compares favorably to both the one-year patient evaluation of the same prostheses ( $88 \%$ and $84 \%$, respectively) [20] and previous studies [63] that recorded a 79\% satisfaction rate in both the fulfillment of expectations and improvement in chewing ability for patients rehabilitated with fixed mandibular full-arch implant-supported fixed prostheses of metal-acrylic resin.

The present study has limitations, including being a single center study, with a small sample size, a short follow-up and absence of a control group, and therefore the results should be interpreted with caution. The strengths of this study relate to the prospective design and the low rate of dropouts $(8 \%)$, rendering increased internal validity. Nevertheless, the dropout rate can significantly influence the survival rate, since patients dropping out have an increased probability of negative outcomes; therefore, the prosthetic survival should be interpreted carefully as it could be overestimated. Future research should aim to examine both the five years outcome and the evaluation of a routine group.

\section{Conclusions}

Based on the results and within the study limitations, the three-year outcome suggests the proposed full-arch hybrid PEEK-acrylic resin fixed rehabilitation solution as a legitimate treatment option, albeit pending lengthier evaluation. The study registered a high prosthetic/implant CSR and patient satisfaction, a low MBL, and low rate of biological and mechanical complications. This treatment modality provides a potential shock-absorbing alternative that could benefit the implant biological outcome, but it should be further studied in a longer follow-up.

\section{Patents}

An International patent resulting from the work reported in this manuscript was issued on 10 January 2019: Silva, A.; Legatheaux, J.; de Araújo Nobre, M.; Guedes, C.M.; Almeida, R.; Maló, P.; Sereno, N. Dental prosthesis. International patent no. WO 2019/008368 A1.

Author Contributions: Conceptualization, M.d.A.N., C.M.G., R.A., A.S. and N.S.; methodology, M.d.A.N.; validation, M.d.A.N, C.M.G., R.A., A.S. and N.S.; formal analysis, M.d.A.N.; investigation, M.d.A.N, C.M.G., R.A., A.S. and N.S.; Writing-Original draft preparation, M.d.A.N.; Writing-Review and editing, M.d.A.N., C.M.G., R.A., A.S. and N.S.; visualization, M.d.A.N., C.M.G., R.A., A.S. and N.S. All authors have read and agreed to the published version of the manuscript.

Funding: This research received funding from Juvora, Ltd. 
Acknowledgments: The authors would like to acknowledge André Rodrigues, José Figueiredo, Filipa Gonçalves, Sandro Catarino, and Luís Gomes for all the help provided in this research.

Conflicts of Interest: This study was supported by Juvora, grant no. 1/2013. Carlos Moura Guedes, Miguel de Araújo Nobre, and António Silva received previous educational fees from Juvora. Nuno Sereno collaborates scientifically with Juvora (an Invibio company). Ricardo Almeida declares no conflicts of interest.

\section{References}

1. Jenkins, M.J. Relaxation behaviour in blends of PEEK and PEI. Polymer 2000, 41, 6803-6812. [CrossRef]

2. Searle, O.B.; Pfeiffer, R.H. Victrex ${ }^{\circledR}$ poly(ethersulfone) (PES) and Victrex ${ }^{\circledR}$ poly(ether ether ketone) (PEEK). Polym. Eng. Sci. 1985, 25, 474-476. [CrossRef]

3. Yurchenko, M.E.; Huang, J.; Robisson, A.; McKinley, G.H.; Hammond, P.T. Synthesis, mechanical properties and chemical/solvent resistance of cross-linked poly(aryl-ether-ether-ketones) at high temperatures. Polymer 2010, 51, 1914-1920. [CrossRef]

4. Rivard, C.H.; Rhalmi, S.; Coillard, C. In vivo biocompatibility testing of peek polymer for a spinal implant system: A study in rabbits. J. Biomed. Mater. Res. 2002, 62, 488-498. [CrossRef] [PubMed]

5. Kurtz, S.M. Implantable PEEK polymers: A decade of progress in spine. Orthop. Des. Technol. 2010, 6, 54-58.

6. Kurtz, S.M.; Devine, J.N. PEEK biomaterials in trauma, orthopedic, and spinal implants. Biomaterials 2007, 28, 4845-4869. [CrossRef]

7. Toth, J.M.; Wang, M.; Estes, B.T.; Scifert, J.L.; Seim, H.B., III; Turner, A.S. Polyetheretherketone as a biomaterial for spinal applications. Biomaterials 2006, 27, 324-334. [CrossRef]

8. El Halabi, F.; Rodriguez, J.F.; Rebolledo, L.; Hurtós, E.; Doblaré, M. Mechanical characterization and numerical simulation of polyether-ether-ketone(PEEK) cranial implants. J. Mech. Behav. Biomed. Mater. 2011, 4, 1819-1832. [CrossRef]

9. Jarman-Smith, M. Evolving uses for implantable PEEK and PEEK based compounds. Med. Device Technol. 2008, 19, 12-17.

10. Stawarczyk, B.; Beuer, F.; Wimmer, T.; Jahn, D.; Sener, B.; Roos, M.; Schmidlin, P.R. Polyetheretherketone- A suitable material for fixed dental prostheses? J. Biomed. Mater. Res. B Appl. Biomater. 2013, 101, 1209-1216. [CrossRef]

11. Stawarczyk, B.; Keul, C.; Beuer, F.; Roos, M.; Schmidlin, P.R. Tensile bond strength of veneering resins to PEEK: Impact of different adhesives. Dent. Mater. J. 2013, 32, 441-448. [CrossRef] [PubMed]

12. Schwitalla, A.; Müller, W.D. PEEK dental implants: A review of the literature. J. Oral Implantol. 2013, 39, 743-749. [CrossRef] [PubMed]

13. Koutouzis, T.; Richardson, J.; Lundgren, T. Comparative soft and hard tissue responses to titanium and polymer healing abutments. J. Oral Implantol. 2011, 37, 174-182. [CrossRef]

14. Sarot, J.R.; Contar, C.M.; Cruz, A.C.; de Souza Magini, R. Evaluation of the stress distribution in CFR-PEEK dental implants by the three-dimensional finite element method. J. Mater. Sci. Mater. Med. 2010, 21, 2079-2085. [CrossRef]

15. Rosentritt, M.; Schneider-Feyrer, S.; Behr, M.; Preis, V. In vitro shock absorption tests on implant-supported crowns: Influence of crown materials and luting agents. Int. J. Oral Maxillofac. Implants 2018, 33, 116-122. [CrossRef]

16. Conserva, E.; Menini, M.; Tealdo, T.; Belivacqua, M.; Ravera, G.; Pera, F.; Pera, P. The use of a masticatory robot to analyze the shock absorption capacity of different restorative materials for prosthetic implants: A preliminary report. Int. J. Prosthodont. 2009, 22, 53-55. [PubMed]

17. Menini, M.; Conserva, E.; Tealdo, T.; Belivacqua, M.; Pera, F.; Ravera, G.; Pera, P. The use of a masticatory robot to analyze the shock absorption capacity of different restorative materials for implant prosthesis. J. Biol. Res. 2011, 84, 118-119. [CrossRef]

18. Najeeb, S.; Zafar, M.S.; Khurshid, Z.; Siddiqui, F. Applications of polyetheretherketone (PEEK) in oral implantology and prosthodontics. J. Prosthodont. Res. 2016, 60, 12-19. [CrossRef]

19. Alexakou, E.; Damanaki, M.; Zoidis, P.; Bakiri, E.; Mouzis, N.; Smidt, G.; Kourtis, S. PEEK high performance polymers: A review of properties and clinical applications in prosthodontics and restorative dentistry. Eur. J. Prosthodont. Restor. Dent. 2019, 27, 113-121. 
20. Maló, P.; de Araújo Nobre, M.; Moura Guedes, C.; Almeida, R.; Silva, A.; Sereno, N.; Legatheaux, J. Short-term report of an ongoing prospective cohort study evaluating the outcome of full-arch implant-supported fixed hybrid polyetheretherketone-acrylic resin prostheses and the All-on-Four concept. Clin. Implant Dent. Relat. Res. 2018, 20, 692-702. [CrossRef]

21. Han, X.; Sharma, N.; Xu, Z.; Scheideler, L.; Geis-Gerstorfer, J.; Rupp, F.; Thieringer, F.M.; Spintzyk, S. An in vitro study of osteoblast response on fused-filament fabrication 3D printed PEEK for dental and cranio-maxillofacial implants. J. Clin. Med. 2019, 31, 8. [CrossRef] [PubMed]

22. Ramenzoni, L.L.; Attin, T.; Schmidlin, P.R. In vitro effect of modified polyetheretherketone (PEEK) implant abutments on human gingival epithelial keratinocytes migration and proliferation. Materials 2019, 12, E1401. [CrossRef] [PubMed]

23. Mishra, S.; Chowdhary, R. PEEK materials as an alternative to titanium in dental implants: A systematic review. Clin. Implant Dent. Relat. Res. 2019, 21, 208-222. [CrossRef] [PubMed]

24. Mounir, M.; Atef, M.; Abou-Elfetouh, A.; Hakam, M.M. Titanium and polyether ether ketone (PEEK) patient-specific sub-periosteal implants: Two novel approaches for rehabilitation of the severely atrophic anterior maxillary ridge. Int. J. Oral Maxillofac. Surg. 2018, 47, 658-664. [CrossRef] [PubMed]

25. Mounir, M.; Shalash, M.; Mounir, S.; Nassar, Y.; El Khatib, O. Assessment of three dimensional bone augmentation of severely atrophied maxillary alveolar ridges using prebent titanium mesh vs customized poly-ether-ether-ketone (PEEK) mesh: A randomized clinical trial. Clin. Implant Dent. Relat. Res. 2019, 21, 960-967. [CrossRef]

26. Maló, P.; Rangert, B.; Dvärsäter, L. Immediate function of Brånemark implants in the esthetic zone: A retrospective clinical study with 6 months to 4 years of follow-up. Clin. Implant Dent. Relat. Res. 2000, 2, 138-146. [CrossRef]

27. Meloni, S.M.; De Riu, G.; Pisano, M.; Cattina, G.; Tullio, A. Implant treatment software planning and guided flapless surgery with immediate provisional prosthesis delivery in the fully edentulous maxilla: A retrospective analysis of 15 consecutively treated patients. Eur. J. Oral Implantol. 2010, 3, 245-251.

28. Malo, P.; de Araújo Nobre, M.; Lopes, A.; Moss, S.M.; Molina, G.J. A longitudinal study of the survival of All-on-4 implants in the mandible with up to 10 years of follow-up. J. Am. Dent. Assoc. 2011, 142, 310-320. [CrossRef]

29. Maló, P.; de Araújo Nobre, M.; Lopes, A.; Francischone, C.; Rigolizzo, M. “All-on-4" immediate-function concept for completely edentulous maxillae: A clinical report on the medium (3 years) and long-term (5 years) outcomes. Clin. Implant Dent. Relat. Res. 2012, 14, e139-e150. [CrossRef]

30. Maló, P.; Lopes, A.; de Araújo Nobre, M.; Ferro, A. Immediate function dental implants inserted with less than $30 \mathrm{~N} \cdot \mathrm{cm}$ of torque in full-arch maxillary rehabilitations using the All-on-4 concept: Retrospective study. Int. J. Oral Maxillofac. Surg. 2018, 47, 1079-1085. [CrossRef]

31. Maló, P.; de Araújo Nobre, M.; Lopes, A.; Ferro, A.; Nunes, M. The All-on-4 concept for full-arch rehabilitation of the edentulous maxillae: A longitudinal study with 5-13 years of follow-up. Clin. Implant Dent. Relat. Res. 2019, 21, 538-549. [CrossRef] [PubMed]

32. Maló, P.; de Araújo Nobre, M.; Lopes, A.; Ferro, A.; Botto, J. The All-on-4 treatment concept for the rehabilitation of the completely edentulous mandible: A longitudinal study with 10 to 18 years of follow-up. Clin. Implant. Dent. Relat. Res. 2019, 21, 565-577. [CrossRef] [PubMed]

33. Maló, P.; Rangert, B.; Nobre, M. "All-on-Four" immediate-function concept with Brånemark System implants for completely edentulous mandibles: A retrospective clinical study. Clin. Implant Dent. Relat. Res. 2003, 5, S2-S9. [CrossRef] [PubMed]

34. Maló, P.; Rangert, B.; Nobre, M. All-on-4 immediate-function concept with Brånemark System implants for completely edentulous maxillae: A 1-year retrospective clinical study. Clin. Implant Dent. Relat. Res. 2005, 7, S88-S94. [CrossRef] [PubMed]

35. Francetti, L.; Agliardi, E.; Testori, T.; Romeo, D.; Taschieri, S.; Del Fabbro, M. Immediate rehabilitation of the mandible with fixed full prosthesis supported by axial and tilted implants: Interim results of a single cohort prospective study. Clin. Implant Dent. Relat. Res. 2008, 10, 255-263. [CrossRef] [PubMed]

36. Agliardi, E.; Clericò, M.; Ciancio, P.; Massironi, D. Immediate loading of full-arch fixed prostheses supported by axial and tilted implants for the treatment of edentulous atrophic mandibles. Quintessence Int. 2010, 41, 285-293. 
37. Agliardi, E.L.; Pozzi, A.; Stappert, C.F.; Benzi, R.; Romeo, D.; Gherlone, E. Immediate fixed rehabilitation of the edentulous maxilla: A prospective clinical and radiological study after 3 years of loading. Clin. Implant Dent. Relat. Res. 2014, 16, 292-302. [CrossRef]

38. Tallarico, M.; Meloni, S.M.; Canullo, L.; Caneva, M.; Polizzi, G. Five-Year Results of a Randomized Controlled Trial Comparing Patients Rehabilitated with Immediately Loaded Maxillary Cross-Arch Fixed Dental Prosthesis Supported by Four or Six Implants Placed Using Guided Surgery. Clin. Implant Dent. Relat. Res. 2016, 18, 965-972. [CrossRef]

39. Hopp, M.; de Araújo Nobre, M.; Maló, P. Comparison of marginal bone loss and implant success between axial and tilted implants in maxillary All-on-4 treatment concept rehabilitations after 5 years of follow-up. Clin. Implant Dent. Relat. Res. 2017, 19, 849-859. [CrossRef]

40. Lopes, A.; Maló, P.; de Araújo Nobre, M.; Sánchez-Fernández, E.; Gravito, I. The NobelGuide ${ }^{\circledR}$ All-on-4 ${ }^{\circledR}$ Treatment Concept for Rehabilitation of Edentulous Jaws: A Retrospective Report on the 7-Years Clinical and 5-Years Radiographic Outcomes. Clin. Implant Dent. Relat. Res. 2017, 19, 233-244. [CrossRef]

41. Tallarico, M.; Canullo, L.; Pisano, M.; Peñarrocha-Oltra, D.; Peñarrocha-Diago, M.; Meloni, S.M. An up to 7-year retrospective analysis of biologic and technical complication with the All-on-4 Concept. J. Oral Implantol. 2016, 42, 265-271. [CrossRef] [PubMed]

42. Ayub, K.V.; Ayub, E.A.; Lins do Valle, A.; Bonfante, G.; Pegoraro, T.; Fernando, L. Seven-Year Follow-up of Full-Arch Prostheses Supported by Four Implants: A Prospective Study. Int. J. Oral Maxillofac. Implants 2017, 32, 1351-1358. [CrossRef] [PubMed]

43. Patzelt, S.B.; Bahat, O.; Reynolds, M.A.; Strub, J.R. The all-on-four treatment concept: A systematic review. Clin. Implant Dent. Relat. Res. 2014, 16, 836-855. [CrossRef] [PubMed]

44. Soto-Penaloza, D.; Zaragozí-Alonso, R.; Penarrocha-Diago, M.; Penarrocha-Diago, M. The All-on-four treatment concept: Systematic review. J. Clin. Exp. Dent. 2017, 9, e474-e488. [CrossRef] [PubMed]

45. Adell, R.; Lekholm, U.; Rockler, B.; Brånemark, P.I. A 15-year study of osseointegrated implants in the treatment of the edentulous jaw. Int. J. Oral Surg. 1981, 10, 387-416. [CrossRef]

46. Maló, P.; Nobre, M.D.; Lopes, A. The rehabilitation of completely edentulous maxillae with different degrees of resorption with four or more immediately loaded implants: A 5-year retrospective study and a new classification. Eur. J. Oral Implantol. 2011, 4, 227-243.

47. Silva, A.; Legatheaux, J.; de Araújo Nobre, M.; Guedes, C.M.; Almeida, R.; Maló, P.; Sereno, N. Input Device. International Patent no. WO 2019/008368 A1, 10 January 2019. Available online: https:/patentscope.wipo.int/ search/en/detail.jsf;jsessionid=0E8C0612BBCE60755A24336CF91C0833.wapp2nA?docId=WO2019008368\& recNum $=8489 \&$ office $=\&$ queryString $=\&$ prevFilter $=\&$ sortOption $=$ Pub + Date + Desc $\&$ max $R e c=73389249$ (accessed on 11 June 2020).

48. Mombelli, A.; van Oosten, M.A.; Schurch, E., Jr.; Lang, N.P. The microbiota associated with successful or failing osseointegrated titanium implants. Oral Microbiol. Immunol. 1987, 2, 145-151. [CrossRef]

49. Tallarico, M.; Cervino, G.; Scrascia, R.; Uccioli, U.; Lumbau, A.; Meloni, S.M. Minimally invasive treatment of edentulous maxillae with overdenture fully supported by a Cad/Cam titanium bar with a low-profile attachment screwed on four or six implants: A case series. Prosthesis 2020, 2, 53-64. [CrossRef]

50. Hsu, Y.T.; Fu, J.H.; Al-Hezaimi, K.; Wang, H.L. Biomechanical implant treatment complications: A systematic review of clinical studies of implants with at least 1 year of functional loading. Int. J. Oral Maxillofac. Implants 2012, 27, 894-904.

51. Nishigawa, K.; Bando, E.; Nakano, M. Quantitative study of bite force during sleep associated bruxism. J. Oral Rehabil. 2001, 28, 485-491. [CrossRef]

52. Calderon, P.D.S.; Kogawa, E.M.; Lauris, J.R.; Conti, P.C. The influence of gender and bruxism on the human maximum bite force. J. Appl. Oral Sci. 2006, 14, 448-453. [CrossRef] [PubMed]

53. Maló, P.; Nobre, M.D.; Lopes, A. Immediate loading of 'All-on-4' maxillary prostheses using trans-sinus tilted implants without sinus bone grafting: A retrospective study reporting the 3-year outcome. Eur. J. Oral Implantol. 2013, 6, 273-283. [PubMed]

54. Del Fabbro, M.; Ceresoli, V. The fate of marginal bone around axial vs. tilted implants: A systematic review. Eur. J. Oral Implantol 2014, 7, S171-S189. [PubMed]

55. Pontoriero, R.; Tonelli, M.P.; Carnevale, G.; Mombelli, A.; Nyman, S.R.; Lang, N.P. Experimentally induced peri-implant mucositis. A clinical study in humans. Clin. Oral Implant. Res. 1994, 5, 254-259. [CrossRef] [PubMed] 
56. Salvi, G.E.; Aglietta, M.; Eick, S.; Sculean, A.; Lang, N.P.; Ramseier, C.A. Reversibility of experimental peri-implant mucositis compared with experimental gingivitis in humans. Clin. Oral Implant. Res. 2012, 23, 182-190. [CrossRef]

57. Rothman, K.J.; Greenland, M.A. Causation and causal inference in epidemiology. Am. J. Public Health 2005, 95, S144-S150. [CrossRef]

58. De Araújo Nobre, M.; Mano Azul, A.; Rocha, E.; Maló, P. Risk factors of peri-implant pathology. Eur. J. Oral Sci. 2015, 123, 131-139. [CrossRef]

59. Albrektsson, T.; Dahlin, C.; Jemt, T.; Sennerby, L.; Turri, A.; Wennerberg, A. Is marginal bone loss around oral implants the result of a provoked foreign body reaction? Clin. Implant. Dent. Relat. Res. 2014, 16, $155-165$. [CrossRef]

60. Keul, C.; Liebermann, A.; Schmidlin, P.R.; Roos, M.; Sener, B.; Stawarczyk, B. Influence of PEEK surface modification on surface properties and bond strength to veneering resin composites. J. Adhes. Dent. 2014, 16, 383-392.

61. Maló, P.; Araújo Nobre, M.D.; Lopes, A.; Rodrigues, R. Double full-arch versus single full-arch, four implant-supported rehabilitations: A retrospective, 5-year cohort study. J. Prosthodont. 2015, 24, 263-270. [CrossRef]

62. Aglietta, M.; Siciliano, V.I.; Zwahlen, M.; Bragger, U.; Pjetursson, B.E.; Lang, N.P.; Salvi, G.E. A systematic review of the survival and complication rates of implant supported fixed dental prostheses with cantilever extensions after an observation period of at least 5 years. Clin. Oral. Implant. Res. 2009, 20, 441-451. [CrossRef] [PubMed]

63. Kennedy, K.; Chacon, G.; McGlumphy, E.; Johnston, W.; Yilmaz, B.; Kennedy, P. Evaluation of patient experience and satisfaction with immediately loaded metal-acrylic resin implant-supported fixed complete prosthesis. Int. J. Oral Maxillofac. Implants 2012, 27, 1191-1198. [PubMed]

(C) 2020 by the authors. Licensee MDPI, Basel, Switzerland. This article is an open access article distributed under the terms and conditions of the Creative Commons Attribution (CC BY) license (http://creativecommons.org/licenses/by/4.0/). 